\title{
URGENSI MENDENGARKAN PENDAPAT ANAK DALAM PENDIDIKAN ISLAM BAGI ORANG TUA MUSLIM PERPEKTIF AL-QURAN DI ERA DIGITAL
}

\author{
Bainar \\ STAI Diniyah Pekanbaru \\ Jl. Kuau No. 01 Sukajadi Pekanbaru \\ bainar1808@gmail.com
}

DOI: 10.46781/al-mutharahah.v17i2.143

\begin{abstract}
Every person has a period and every era has a person, this is the right term we might say in Islamic education so that parents or educators can realize that education needs to keep up with the times that exist between these generations, not impose their will and not ignore children's opinions. Everything needs to be discussed. Every child's age must experience stages in the development of both affective, cognitive, and physics motor in their life, one of which is the development of religious values. The modernization of the times has an impact on decreasing awareness of the importance of religious values for children in the digital era, habituation is needed from an early age in the parents' family as teachers. Listening to children's opinions with full consideration to make decisions in the world of Islamic education is very important for parents to be able to understand their needs, complaints according to the times they are facing so that they are full of confidence in their future. If parents do not listen to their children, the child's development will be influenced by digital in choosing their view of life so that parents will regret it forever. This research was conducted to find out how important it is to implement deliberation to achieve the goals of Islamic education.
\end{abstract}

Keywords: Urgency; Islamic Education; Digital Age

\begin{abstract}
Abstrak
Setiap orang ada zamanya dan setiap zaman ada orangnya, inilah istilah yang tepat kita kemungkakan dalam pendidkan Islam agar orang tua atau pendidik bisa menyadari bahwa pendidikan itu perlu mengikuti perkembangan zaman yang ada peda generasi tersebut, tidak memaksakan kehendak dan tidak mengabaikan pendapat anak. Segala sesuatu perlu dimusyawarhkan. Setiap usia anak pasti mengalami tahapan pada perkembangan baik afektfi, coknitif dan fisikomotor dalam hidupnya, salah satunya adalah perkembangan nilai agama. Modernisasi zaman, berdampak pada menurunnya kesadaran tentang pentingnya nilai keagamaan bagi anak pada era digital perlu dilakukan pembiasaan sejak dini di dalam keluarga orang tua sebagai gurunya. Mendengarkan pendapat anak dengan penuh pertimbangan untuk mengambil suatu keputusan dalam dunia pendidikan Islam sangatlah penting bagi orang tua untuk dapat memahami kebutuhan, keluhannya sesuai dengan zaman yang mereka hadapi agar penuh percaya diri dalam menatap masa depanya. Jika orang tua tidak mendengakan anaknya maka perkembeangan anak akan dipengaruhi oleh digital dalam memmilih pandangan hidupnya sehingga orang tua akan menyesal selamanya. Penelitian ini dilaksanakan untuk mengetahui betapa pentinngya mengimplementasikan bermusyawarah untuk mencapai tujuan pendidikan Islam.
\end{abstract}

Kata Kunci: Urgensi; Pendidikan Islam; Era Digital 


\section{A. PENDAhuluan}

Setiap orang tua yang normal pasti mendambakan seorang anak, karena anak selain pelanjut garis keturunan anak juga sebagai harapan di dunia untuk menumpang hidup di hari tua dikala kita tak berdaya lagi baik secara materi dan moril, bahkan sampai akhirat nanti ketika alam kehidupan kita telah berpindah disaat tidak ada bantuan dan pertolongan hanyalah bantuan dan pertolongan dari anak-anak yang sholeh dan sholeha melalui do'a untuk orang tuanya. Hal ini tentu dapat kita raih apabila orang tua mampu mendidik anaknya sesuai dengan tuntunan ajaran Islam dengan mempertimbangkan perkembangan anak, baik perkembangan dirinya maupun perkembangan zaman yang dilewatinya saat ini. Karena khalifah Urasyidin Umar bin Khatab pernah berpesan "Didiklah anakmu sesuai dengan zamannya". Selanjutnya Allah berfirman dalam surat An-Nahl ayat 78 yaitu :

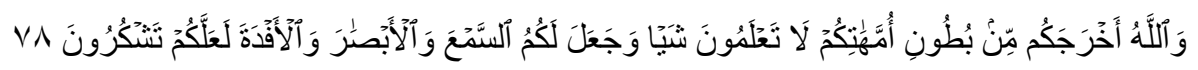

Artinya: "Dan Allah mengeluarkan kamu dari perut ibumu dalam keadaan tidak mengetahui sesuatupun, dan Dia memberi kamu pendengaran, penglihatan dan hati, agar kamu bersyukur".

Melalui ayat diatas, bahwa ketika seorang manusia yang akan dilahirkan didunia tidak akan mengetahui apapun, agar manusia bisa mengetahui sesuatu, Allah SWT telah melengkapi manusia berupa telinga agar bisa mendengan dan didengarkan, diberi mata agar bisa melihat dan hati agar bisa merasa dan memimbang rasa.

Anak adalah adalah anugrah terindah yang di titipkan Allah SWT. Kepada kedua orang tuanya dan tidak ternilai harganya bila di bandingkan harta dan apapun yang perlu kita jaga dan kita pelihara sesuai dengan tuntunan ajaran Islam salah satu caranya adalah dengan pendidikan. Pendidikan yang pertama kali diperoleh anak adalah dari orang tua didalam lingkungan rumah tangga. Dalam menentukan pendidikan buah hati, pastikan bahwa fitrah anak tersebut dapat menemukan lingkungan yang kondusif untuk tumbuh kembang sesuai tuntunan Ilahi Ilahi Rabbi dan Rasul-Nya. Lingkungan yang tidak hanya berorientasi pada capaian akal, yaitu nilai akademis yang tinggi, tetapi juga berorientasi pada capaian spiritual, yaitu nilai aqidah dan akhlak yang baik. Lingkungan yang tidak hanya berorientasi pada capaian fisik yang sehat dan kuat, tetapi berorientasi juga pada capaian hati dan jiwa anak yang mulia. Yaitu pendidikan yang holistik, yaitu pendidikan yang menerapkan olah religi untuk kecerdasan spiritual, olah rasio untuk kecerdasan akal, olah rasa untuk kecerdasan emosional dan juga raga untuk kecerdasan fisik. Kehidupan seorang anak sebagian besar hidupnya yaitu bersama keluarganya. Keluarga sangatlah penting bagi kehidupan anak karena didalam keluarga ada orang tua yang akan mendidik dan membina anak-anaknya kedalam kehidupan yang lebih baik. Semua prilaku anak diawasi oleh orang tua, dari dia kecil sampai dia tumbuh dewasa dan memiliki keluarga dia sendiri mempunyai istri dan anak. Peran inilah yang sebagai orang tua harus mendidik anaknya dari ajaran agama Islam.

Keluarga Islami adalah sebuah bentuk keluarga yang berusaha menerapkan ajaran Rasulullah SAW. Mengingat beliau selalu mengajarkan sikap berakhlak baik kepada keluarga. Keluarga Islami bukanlah hanya menitikberatkan pada status agama dari anggotaanggota keluarga. Dapat dikatakan embel-embel "Islami" menandaskan bahwa keluarga yang bersangkutan membudayakan sunnah yang diajarkan Rasulullah SAW disetiap harinya. Keluarga islami bukan hanya sekedar berdiri di atas kenyataan karena seringnya terdengar lantunan ayat-ayat Al-qur'an dari rumah itu, bukan pula sekedar anak-anaknya disekolahkan ke masjid waktu sore hari. Keluarga islami adalah rumah tangga di dalamnya ditegakkan adab-adab Islami, baik yang menyangkut individu maupun keseluruhan anggota rumah tangga. keluarga islami adalah sebuah rumah tangga yang didirikan di atas landasan ibadah. Mereka bertemu dan berkumpul karena Allah SWT, saling menasehati dalam kebenaran dan kesabaran. Keluarga secara sinonimnya ialah rumah tangga, dan keluarga adalah satu institusi 


\section{Al-Mutharahah: Jurnal Penelitian dan Kajian Sosial Keagamaan}

Vol. 17 No. 2. Juli-Desember 2020

sosial yang berasas karena keluarga menjadi penentu (determinant) utama tentang apa jenis warga masyarakat. ${ }^{1}$

Pendidikan keluarga ialah ruang pembelajaran pertama yang diperoleh anak dari dia kecil sampai dewasa itu adalah asuhan dari orang tua, pendidikan sangat penting terhadap pembentukan kepribadian dan kecerdasaan anak bahkan keberhasilan dan kegagalan pendidikan keluarga dapat menentukan keberhasilan atau kegagalan anak dizaman yang akan mendatang. Ketika pendidikan yang diberikan keluarga kepada anak baik, maka anak akan tumbuh menjadi pribadi yang baik, mempu meneriman hal-hal baik serta memiliki imun atau pemikiran yang kuat untuk tidak menerima hal-hal buruk dilingkungan sekitar yang dijalaninya. Maupun sebaliknya, ketika keluarga memberikan pendidikan yang buruk ke anaknya, maka anak akan dapat tumbuh menjadi pribadi yang buruk, dapat menyerap dan menerima hal-hal negatif diluar sana. Dari hal itu sangatlah penting bagi orang tua memberikan prilaku, pendidikan dan pengajaran yang baik ke anak, biar disaat dewasa dia tau mana yang baik dan mana hal yang buruk. Dan dia bisa menjadi diri yang mampu menjaga dirinya dan keluarga nya. Terdapat tiga sistem pendidikan yang dapat membentuk anak menjadi manusia yang baik atau seutuhnya seperti pendidikan keluarga, masyarakat dan sekolah.

Pendidikan Islam khususnya pendidikan terhadap anak sangat banyak mengajarkan kepada orang tua betapa pentingnya menjadi figur dalam membentuk kepribadian anak yang lebih baik supaya anak tumbuh menjadi figur yang mendidik dan membesarkanya. Keluarga muslim harus menjalani keluarga yang mengikuti literatur agama, baik Al-qur'an, hadis dan literatur lain yang secara detail atau spesifik yang membahas tentang tata cara mendidik anak dalam perspektif Islam yang sangat berkaitan dengan keberhasilan orang tua dalam pertumbuhan dan perkembangan anak menjadi pribadi yang ideal. Sehingga akan tercipta anak-anak dengan kondisi fisik yang sehat, berkepribadian dan prilaku yang baik, kematangan emosi, mental, cerdas, psikologis dan berimplikasi positif terhadap lingukangan sekitar dan tempat tinggalnya. Kemudian setelah anak-anak yang ideal yang didik oleh orang tua lahir dan tumbuh, sehingga halayak atau masyarakat akan mengetahui bahwa pendidikan anak dalam perspektif agama Islam benar-benar berpotensi sangat besar dalam membentuk anak menjadi manusia seutuhnya dan tidak akan mustahil akhirnya literatur pendidikan Islam akan sangat diminitati oleh kalangan keluarga Islam dan bahkan hingga di luar agama Islam karena dianggap dapat dijadikan sebagai cara mendidik anak yang lebih baik dan ideal. Oleh karena itu, urgensi pendidikan keluarga di dalam perspektif Al-qur'an, hadis dan psikologi perkembangan anak perlu dikaji lebih mendalam².

Pada dizaman sekarang atau zaman teknologi, aspek dari luar sangat memengaruhi keluarga semakin bersar, seperti era digital yang ditandai dengan kemajuan ilmu pengetahuan dan teknologi yang sangat pesat perkembangannya, selain berdampak positif bagi keluarga juga bisa berdampak negatif. Di antara masalah yang dihadapi keluarga ialah renggangnya hubungan keluarga akibat individual yang sering kali menimbulkan kesenjangan hubungan antara suami istri, antara orang tua dan anak (terutama anak yang sudah beranjak dewasa) yang biasa disebabkan oleh gadget, bermain sosial media dll. Sehingga membuat keluarga bisa sibuk sendiri" dengan gadget nya. Berkurangnya peran dari orang tua dalam membimbing dan mengawasi anak karena orang tua masing-masing ibu dan ayah terlalu sibuk sehingga anak merasa kurang diperhatikan, dicintai dan merasa tika mendapatkan kasih

${ }^{1}$ Bahrun Ali Murtopo, "MANAJEMEN ORANG TUA DALAM PENDIDIKAN ANAK KELUARGA MUSLIM ( Studi Kasus Di Wotbuwono, Klirong. 4 Keluarga)," AWLADY: Jurnal Pendidikan Anak 3, no. 2 (2017): 58, https://doi.org/10.24235/awlady.v3i2.1773.

2 Wardatul Asfiyah and Lailul Ilham, "Urgensi Pendidikan Keluarga Dalam Perspektif Hadist Dan Psikologi Perkembangan," Hisbah: Jurnal Bimbingan Konseling Dan Dakwah Islam 16, no. 1 (2019): 1-20, https://doi.org/10.14421/hisbah.2019.161-01. 
sayang, pada hal cinta dan kasih sayang yang tulus adalah dambaan bagi setiap nanak agar mereka bertahan dalam memperjuangkan dan mengahadapi kehidupanya dimasa depan. Disamping itu, berubahnya sikap terhadap norma-norma agama dan sosial budaya yang bisa berlaku dalam sebuah keluarga sehingga muncul kecendrungan berahlinya sistem kekeluargaan. Fungsi keluarga tak dapat dilakukan, karena kebanyakan anak menjadi nakal atau melakukan kejahatan seperti geng motor, bermain game online, tawuran, berkelahi, mencoba memakai narkoba, membuli atau menghajar tanpa memiliki rasa kasihan terhadap teman-temannya dan tanpa memikirkan akibatnya terhadap dirinya dan keluarganya, hal ini biasa terjadi pada anak yang memiliki kekerasan fisik pada keluarga yang tidak harmonis atau berantakan. temanya dan memikirkan akibatnya terhadap dirin dan keluarganya, hal ini terjadi kekerasan fisik pada keluarga yang berantakan.

Mendengar dan didengar adalah sebuah proses komunikasi yang efektif. Dalam berkomunikasi, tidak bisa seseorang hanya mau didengar, ia juga harus mendengarkan orang lain agar bisa menciptakan sebuah komunikasi dua arah dan terhindar dari salah paham. Akan tetapi, di berbagai kasus, orang lebih ingin didengar daripada mendengar. Terlebih jika lawan bicara adalah anak kita sendiri. Sebagai orangtua, kita sering merasa bahwa anak harus mendengarkan kita. Tanpa diminta pendapatnya, orangtua sering kali memberikan nasihat atau larangan pada anaknya. Kita selalu menganggap bahwa kita sudah punya bekal pengalaman hidup yang cukup untuk memberikan nasihat atau perintah kepada anak-anak. Dalam hal tertentu, orangtua terlalu memaksakan kehendaknya tanpa meminta pertimbangan anak. Pada posisi ini, tanpa sadar orangtua lebih mendominasi komunikasi tampa memikirkan perasaan anak, akhirnya anak melarikan diri untuk menyelesaikan permasalahnya melalui teknologi kadang kala tampa memilah dan memilih apakah itu baik atau tidak buat dirinya diamasa akan datang kadangkala hanya kebahagian sesa'at saja. Tidak adanya komunikasi, banyak orang tua yang sibuk dengan dirinya sendiri, sedikit sekali waktu untuk bisa berkomunikasi dengan anaknya, terkadang acara berkumpul dengan keluargapun orang tua masih disibukan dengan menelepon teman atau rekan kerja dan anak sibuk sendiri dengan gadget nya dan bermain game online. Padahal orang tua yang mampu menjalin komunikasi yang baik, akan sangat bermanfaat bagi perkembangan prilaku dan emosi anak terutama perkembangan identitas dirinya serta pembiasaan untuk selalu berskipa terbuka dengan orang tuanya dan orang lain. Orang tua hanya menuntuk dan memaksa kehendak serta keinginannya sendiri tanpa mendengarkan pendapat anak tentang keinginannya. Berdasarkan permasalahan ilmiah ini, penulis merasa tertarik untuk mengkaji lebih jauh urgenya mendengarkan pendapat anak dalam pendidikan Islam bagi orang tua di era digital

\section{B. METODE PENELITIAN}

Dalam metode penelitian adalah suatu cara untuk mencari dan mengolah data dan membahas data agar dapat memecahkan suatu permasalah yang sedang dihadapi dalam mengerjakan jurnal ini. Penelitian ini dilakukan dengan cara pengumpulan data-data yang dilakukan dengan cara membaca, memahami, dan mencatat hal-hal yang berkaitan dengan permasalahan yang sedang dilakukan dengan cara melalui sumber-sumber primer maupun sumber-sumber skunder seperti, dari buku-buku, jurnal-jurnal yang berkaitan dengan penelitian ini.

\section{PEMBAHASAN}

1. Teori Tentang Mendengarkan Pendapat Anak

Anak butuh didengarkan, agar kita tahu apa sebearnya yang sedang dirasakan dan diinginkannya, apa yang sedang dikeluhkan dan tidak diinginkannya, sehingga anak akan selalu terbuka dan mau berkomunikasi. Sehingga kita akan mampu membangun dan mengembangkan bakat dan potensinya secara alami. Semakin banyak kita mendengarkan pendapat anak, maka semakin kita tahu apa yang Allah berikan untuk anak kita. Anak 


\section{Al-Mutharahah: Jurnal Penelitian dan Kajian Sosial Keagamaan}

Vol. 17 No. 2. Juli-Desember 2020

sangatlah membutuhkan perhatian, anak malas bicara apabila orang dewasa tidak mendengarkannya dengan baik. Dengan hal itu, sangat penting bagi orang tua untuk menunjukkan sikap menghargai saat anak berbicara. Kalau orang tua mau mendengarkan pendapat anak tanpa prasangka, maka akan tumbuh keyakinan pada diri anak bahwa dirinya tidak akan merasa ditolak dan disakiti.

Ayah dan ibu sebagai orang tua sangat diharapkan menjadi sebuah tim yang bisa menciptakan keluarga sehat secara mental dan emosional, dimana setiap anggota keluarganya saling bertanggung jawab dan berhasil membuat kebahagian bersama melalui pengalaman, kasih sayang, terciptanya kehidupan keluarga yang positif, dan lain-lain. Untuk memeroleh kebahagian tersebut, yaitu dengan cara bergantung pada keharmonisan komunikasi antara anggota keluarga yaitu ayah, ibu dan anak. Namun hampir semua orang tua beranggapan bahwa mencapai kebahagian dan keberhasilan seorang anak adalah tujuan yang susah dan sulit untuk dicapai orang tua. ${ }^{3}$ Seperti, suami istri memiliki rasa yang saling peduli, tidak otomatis di antara mereka saling mendukung anak dalam komunikasi dengan anggota di keluarganya. Salah satu masalah yang dihadapi oleh orang tua sekarang dalam berkomunikasi dengan anak terutama anak remaja adalah bagaimana cara menumbuhkan sikap anak mendengarkan dan memahami mengikuti nasehat orang tuanya untuk menciptakan dan mewujudkan potensi dirinya secara maksimal dan bisa mengontrol emosional nya terhadap orang lain. Satu hal yang sangat sulit dilakukan oleh anak-anak pada zaman sekarang. Dengan hal ini mendengarkan pendapat anak bagi orang tua sangatlah penting, jika orang tua tidak mendengarkan pendapat anak, maka anak itu bisa tidak mendengarkan lagi pendapat orang tua ketika pendapat dia (anak) tidak didengarkan. Cobalah pahami dan perhatikan tentang kewajiban berbakti dan bersikap baik, berakhlak mulia kepada ibu bapak ini. Karena manusia itu apabila, telah berumah tangga sendiri, beristeri dan beranak-pinak, sering kali tidak memperhatikan lagi ta`at kepada kedua orang tuanya. Harta benda dan anak keturunan sering kali menjadi fitnah dan ujian bagi manusia di dalam perjuangan hidupnya, di sanalah kasih sayang orang tuanya kepada anaknya. Namun anak yang telah berdiri sendiri itu sering lalai memperhatikan orang tuanya.

Dalam lingkungan keluarga masyarakat lebih menekankan memberi instruksi kepada anak-anak daripada mendengarkan mereka. Padahal spiritualitas anak-anak perlu dirawat, dijaga agar tetap hidup, bukan disingkirkan demi kenyataan praktis. Daripada selalu mengatur kehidupan anak dan mengamati mereka dari luar, lebih baik menciptakan hubungan berdasarkan kebijaksanaan intuitif anak dan oarangtua. Sehingga dapat membangun kekeluargaan yang lebih kaya. Anak-anak dikaruniai dengan persepsi bawaan yang jernih. Dengan mendengarkan, memahami, dan menghormati berkah ini, akan memperkaya dunia anak-anak dan dunia tempat kita mendengarkan. Anak-anak adalah pengamat yang baik, reseptif, dan sadar serta kita dapat berbagi sebagian kesadaran itu dengan mendengarkan mereka. Mereka mempunyai karunia bawaan berupa pandangan batin. Seorang anak melihat hal-hal di dunianya yang kita mungkin tidak dapat melihatnya. Berbicara dengan orang dewasa yang reseptif tentang apa yang dirasakannya memberi dunianya suara dan memberinya pembendaharaan kata untuk pengalamannya yang kaya dan gagasan uniknya. ${ }^{4}$

Mendengar pendapat anak dapat menjadi cara termudah bagi orang tua lakukan, karena mendengar pendapat anak bisa mengerti keadaan anak dan kemauan anak. Mendengar tidak perlu menyiapkan keahlian dan kekuatan khusus. Dengarkan apa saja yang dikatakan anak, pahami apa yang diinginkan anak agar kita memahami apa yang diinginkan anak kita

\footnotetext{
${ }^{3}$ Anne Ratnasari, "Komunikasi Harmonis Orang Tua Dengan Anak," Mediator: Jurnal Komunikasi 8, no. 2 (2007): 345-52, https://doi.org/10.29313/mediator.v8i2.1247.

${ }^{4}$ Hasan Bastomi, "Pendidikan Keluarga Melalui Keterampilan Mendengar: Studi Kasus Di Wedung, Demak," BUANA GENDER: Jurnal Studi Gender Dan Anak 1, no. 2 (2016): 189, https://doi.org/10.22515/bg.v1i2.403.
} 
sendiri. Dengan banyak orang tua meluangkan waktunya kepada anak, mendengarkan keinginan, kegelisahan dan pendapatnya, anak sangat merasa dihargai, diperhatikan dan mendapatkan kasih sayang yang tulus. Semua ini kelak akan berguna saat mereka dewasa nanti, dan akan menerapkan apa yang dilakukan orang tua kepada anaknya, seperti bisa mendengarkan pendapat orang lain, pendapat teman-temannya, bisa menghargai yang dilakukan orang lain, dan juga menambahkan kedewasaan pada dirinya.

2. Teori Tentang Pendidikan Islam Bagi Anak Dalam Bimbingan Orang Tua

Keluarga ialah tempat pendidikan pertama dan yang mendidiknya adalah kedua orang tua. Orang tua (bapak dan ibu) ialah pendidik alami bagi anak-anaknya karena secara kodrat nya ibu dan bapak di berikan oleh Allah yaitu naluri orang tua sebagai pelindung dan pendidik anak-anaknya dari dia kecil sampai dia dewasa yang dapat menentukan hidup nya sendiri. Dengan naluri orang tua ini timbul rasa kasih sayang para orang tua kepada anak-anak dari secara moral keduanya terbebani rasa tanggung jawab untuk membimbing anak-anaknya. Pendidikan dalam keluarga akan menciptakan jiwa keagamaan seorang anak. Rasulullah menekankan tanggung jawab kepada orang tua untuk mendidik anak-anaknya, karena orang tua bisa membentuk arah keyakinan anak-anaknya. Orang tua ialah orang pertama yang mengajarkan semua hal kepada anaknya, dari pendidikan, moral dan kepribadian.

Orang tua memiliki tanggung jawab yang besar mengenai pendidikan anak di dalam keluarga. Anak siap menerima pengaruh dari luar berupa pendidikan dari orang tuanya. Dalam Islam sebagai agama rahmatan lil 'alamin mempunyai langkah-langkah mendidik anak yang menjadi solusi dalam keluarga sesuai dengan petunjuk al-Qur'an dan al-Hadits. Setiap mendidik anak dari kecil hingga dewasa orang tua harus menerapkan pola mendidik yang berbeda sesuai dengan usia anak-anaknya. Hal ini sangat penting diperhatikan sebagai orang tua yang ingin menciptakan tumbuh kembang anak yang baik dan efektif. Tanggung jawab orang tua mendidik anak sangat panjang dari bayi sampai hingga umur 21 tahun. Pendidikan agama Islam akan menjadi kebutuhan dalam kehidupan umat Islam sangat diperlukan orang tua untuk mendidik anak-anaknya, karena pendidikan agama Islam akan menciptakan anak menjadi orang yang lebih baik dari dunia dan akhirat. Ketika seorang anak tidak diajarkan orang tua tentang pendidikan agama Islam, maka anak akan menjadi pribadi yang buruk. Dari itu orang tua harus mengajarkan anaknya pendidikan Islam. Pengembangan pendidikan agama Islam ini akan mengemuara pada satu roh, yaitu sisi tauhid atau keyakinan terhadap Allah swt sang pencipta alam semesta. Orientasi pendidikan Islam dimulai dengan pencerminan yang secara konprehensif dilakukan pada umat Islam untuk anak nya, dalam berbagai bidang mulai dari ibadah, sejarah, akidah dan pengembangan keilmuan alam dan sosial menuju pendewasaan seorang anak yang religius.

3. Teori Tentang Perspektif Al-Qur'an di Era Digital

Pendidikan agama Islam selama ini telah melakukan transformasi dari segi metode dan strategi pengembangan pendidikan Islam agar menjadi relevan dengan situasi dan kondisi zaman di era digital. Al-Qur'an dan Hadis yang berpijak para tujuan pendidikan nasional, dan filosofi. Pendidikan Islam selama ini telah melakukan transformasi pada tataran paradigma, metode dan strategi pengembangan pendidikan Islam agar menjadi kekinian dan relevan dengan situasi dan kondisi global. Dan tetap dalam koridor cita-cita dan tujuan pendidikan yang bersandar pada Al-Qur'an dan Hadits serta berpijak pada tujuan pendidikan nasional, dasar negara dan filosofi. Pendidikan Islam, memberi pemahaman bahwa "nilai-nilai " Islam menjadi landasan aktivitas belajar, orientasi pembelajaran, serta arah dan perubahan yang direncanakan pada tingkah laku peserta didik, termasuk komunikasi pendidikan dan pembalajaran yang dilakukan harus mengacu pada prinsip-prinsip Al-qur'an dan sunnah serta terbuka untuk unsur-unsur luar secara adaptif yang ditilik dari persepsi ke Islaman.

Pendidikan Islam bertranformasi dengan diorientasikan kepada pendidikan karakter. Penerapan metode pendidikan karakter bagi anak, menurut AlGhazali (Latif, 2016) dengan: 


\section{Al-Mutharahah: Jurnal Penelitian dan Kajian Sosial Keagamaan}

Vol. 17 No. 2. Juli-Desember 2020

(1) Ceramah, (2) Penuntunan dan hafalan, (3) Diskusi, (4) Bercerita, (5) Keteladanan, (6) Demonstrasi, (7) Rihlah (perjalanan untuk mendapatkan pendidikan akhlak), (8) Pemberian tugas, (9) Mujahadah dan riyadhoh, (10) Tanya jawab, (11) Pemberian hadiah dan hukuman. Sedangkan menurut Ratna Megawangi, penerapan metode pendidikan karakter dilakukan dengan mengetahui, mencintai, menginginkan dan mengerjakan karakter adalah sesuatu yang ada yang harus diketahu dicintai diinginkan dan dikerjakan. ${ }^{5}$

\section{SIMPULAN}

Urgentnya mendengarkan anak dalam pendidikan Islam, karena tumbuh kembangnya anak tak terlepas dari peranan orang tua sebagai orang yang pertama mengajarkan anak dirumah dan sekaligus guru yang ia idolakan baik dan buruknya anak tak terlepas dari bagaimana orang tua mendidiknya, sehingga dapat dikatakan anak adalaha cerminan dari orang tuanya.

Setiap orang tua muslim sangat menginginkan seorang anak yang baik sesuai dengan ajaran agama Islam, sebagai orang tua muslim tentu menginginkan anaknya bahagia dunia dan akhirat sesuai tujuan pendidikan Islam itu sendiri. Namun sebagai orang tua kadangkala kita lupa akan kurang menyadari dalam mendidik anak tentang sesuatu dianggap kurang penting, tetapi sangat penting dan berharga bagi anak yaitu "mendengarkan pendapatnya (bermusyawarah)". Ketika anak merasa diabaikan, dicuekan dan tidak diperhatikan, maka anaka melepaskan segala keluh kesah nya ke teknologi seperti bermain gadget, sosial media, bermain game dan lain-lain. Melalui teknologi media yang belum tentu memberikan solusi terbaik terhadap permasalahan yang di alaminya malah kadang kala memberikan pengaruh jahat terhadap anak yang sedang labil mudah terpengaruh, akhirnya terjerumus kepada hal-hal yang tidak sesuai dengan tuntunan dan nilai-nilai agama yang telah dijelaskan Al-Qur'an dan Sunnah dan tujuan pendidikan Islam bahagia dunia akhirat malah mendapat kerugian.

\section{DAFTAR PUSTAKA}

Asfiyah, Wardatul, and Lailul Ilham. "Urgensi Pendidikan Keluarga Dalam Perspektif Hadist Dan Psikologi Perkembangan." Hisbah: Jurnal Bimbingan Konseling Dan Dakwah Islam 16, no. 1 (2019): 1-20. https://doi.org/10.14421/hisbah.2019.161-01.

Bastomi, Hasan. "Pendidikan Keluarga Melalui Keterampilan Mendengar: Studi Kasus Di Wedung, Demak." BUANA GENDER : Jurnal Studi Gender Dan Anak 1, no. 2 (2016): 189. https://doi.org/10.22515/bg.v1i2.403.

Murtopo, Bahrun Ali. "MANAJEMEN ORANG TUA DALAM PENDIDIKAN ANAK KELUARGA MUSLIM ( Studi Kasus Di Wotbuwono, Klirong. 4 Keluarga)." AWLADY: Jurnal Pendidikan Anak 3, no. 2 (2017): 58. https://doi.org/10.24235/awlady.v3i2.1773.

Priyanto, Adun. "Pendidikan Islam Dalam Era Revolusi Industri 4.0." J-PAI: Jurnal Pendidikan Agama Islam 6, no. 2 (2020): 80-89. https://doi.org/10.18860/jpai.v6i2.9072. Ratnasari, Anne. "Komunikasi Harmonis Orang Tua Dengan Anak." Mediator: Jurnal Komunikasi 8, no. 2 (2007): 345-52. https://doi.org/10.29313/mediator.v8i2.1247.

\footnotetext{
${ }^{5}$ Adun Priyanto, "Pendidikan Islam Dalam Era Revolusi Industri 4.0," J-PAI: Jurnal Pendidikan Agama Islam 6, no. 2 (2020): 80-89, https://doi.org/10.18860/jpai.v6i2.9072.
} 